\title{
Real tense and real aspect in mirativity
}

\author{
Teresa Torres Bustamante \\ Rutgers University
}

\begin{abstract}
The goal of this paper is an account of the role of tense and aspect in mirative constructions in Spanish. I propose that the past tense morphology and the imperfect/perfect morphology in Spanish miratives contribute their standard meanings to the semantics of mirativity. I define mirativity as the clash between the speaker's previous beliefs and the current state of affairs asserted by the proposition. I propose an $\mathrm{M}$ operator that relates the speaker's beliefs and the proposition by ranking the worlds in which the proposition doesn't hold in the speaker's previous beliefs as better ones. The past tense is interpreted outside the proposition and constitutes the time argument of the modal base (doxastic domain). Aspect gets its usual interpretation in the proposition but also in the alternative propositions that order the worlds in the modal base. This way, differences regarding the imperfect mirative and the pluperfect one are accounted for. Finally, the paper also discusses stative miratives, which apparently challenge part of the analysis. I claim that these are not counterexamples, but rather confirmation of the analysis, once we account for the interaction between miratives, statives and lifetime effects.
\end{abstract}

Keywords: Mirativity, tense, aspect, Spanish, fake past, lifetime effects, statives

\section{Introduction}

Mirativity is the grammatical category that encodes the speaker's surprise due to new and unexpected information (DeLancey 1997). In Spanish, the past imperfective can express surprise about present habits or states, as we see in (1).

(1) a. ¡Juan fumaba!

Juan smoke-past.imp.3sg

'Juan smokes!' (Context: you see Juan lighting a cigarrete and you

realize he has the habit of smoking, something that you didn't expect.)
b. ¡Eras
alto!

\footnotetext{
* Special thanks to Veneeta Dayal for all her suggestions and comments in every step of the research and writing process. Thanks also to Mark Baker and Liliana Sanchez, as well as to the audiences at MACSIM 2012 and SALT 22.
} 
Torres Bustamante

be.past.imp.2sg tall

'You are tall!' (Context: you are introduced to Juan and you realize he's tall, something that you didn't expect.)

This is puzzling because the 'normal' declarative counterpart of the imperfect is about past habits or past ongoing eventualities, as we see in (2).

\section{(2) Juan fumaba.}

Juan smoke-past.imp.3sg

'Juan used to smoke./Juan was smoking.'

In (1), we notice that the past tense morphology is 'fake' (as defined in Iatridou 2000), since there is not a past interpretation, but rather a present one. Aspect does keep its normal contribution to the assertion, since the sentence in (1) is still a habitual, a meaning expected for imperfective morphology. However, as we will see later in the paper, Andean Spanish also makes use of the pluperfect for expressing mirativity and it does show differences with respect to the imperfect mirative. The main question this paper addresses is what is the role of tense and aspect in the meaning of mirativity.

In this paper, I focus on the meaning of surprise related to these mirative constructions and how the tense and aspect morphology contribute to it. The main intuition is that the 'fake' past tense is not really fake, but rather real past tense interpreted outside the proposition. This is extended to aspect as well. The proposal consists, first, of characterizing mirativity as the clash between speaker's previous beliefs (up to the speech time) and the current state of affairs. This is translated into an operator $\mathrm{M}$ (placed in the $\mathrm{CP}$ domain) that relates the set of speaker's beliefs and the asserted proposition. M ranks the worlds in which the proposition holds as worse worlds than the ones in which the proposition does not hold. $\mathrm{M}$ also asserts the proposition as true in the actual world (miratives are always factive). This clash triggers the sense of surprise. Second, the past tense morphology is reinterpreted as the time argument of the modal base, which gives the speaker's beliefs a past status. Third, aspect makes its contribution via the set of alternatives the asserted proposition is contrasted with. This way, for the imperfect mirative, the set of alternatives consists of imperfect propositions, which are generic sentences, habituals or states; for the pluperfect case, only perfect(ive) propositions, which are episodic events or result states. This contrast is what is going to set apart meaning differences regarding these two miratives in Spanish.

The structure of the paper is as follows. Section 2 discusses the meaning of mirativity and presents the $\mathrm{M}$ operator. Sections 3 accounts for the role of tense, and section 4 extends this analysis to the pluperfect mirative. Section 5, first, explains the relevant contrast between miratives, and second, develops the role of 
Real tense and real aspect in mirativity

aspect in these differences. Section 6 discusses in detail the status of statives in mirativity. Section 7 concludes the paper.

\section{The M operator}

I claim that the surprise encountered in mirative constructions arises as a clash between the speaker's previous beliefs and the current state of affairs, which is discovered at the speech time. The surprise itself is not encoded in mirativity, but rather is a pragmatic consequence triggered by this clash.

As we see below, the mirative sentence expresses the speaker's surprise at the speech time. It is also factive: what is asserted is considered true by the speaker, as showed in (3).

\section{(3) ¡Eras alto! \#De hecho, no lo eres. \\ be-Past Imp. $2 \mathrm{~s}$ tall in fact, no it be.PR.2sg \\ 'You're tall! In fact, you're not.'}

So, we have to take into account both the factivity triggered by the assertion, and the speaker's previous beliefs regarding the proposition. The operator M I propose relates both the assertion $q$ and the speaker's set of beliefs. The proposition $q$ is asserted against a background of beliefs which is structured by an ordering relation that places not- $q$ worlds above $q$ worlds. A first version of the surprise operator $\mathrm{M}$ is given in (4).

$$
\begin{aligned}
& \text { (4) } \left.\mathrm{M}_{\mathrm{op}}=\lambda \mathrm{p} \lambda \mathrm{q}\left[\left[\forall \mathrm{w}^{\prime} \mathrm{w}\left[\mathrm{p} \cap \neg \mathrm{q}\left(\mathrm{w}^{\prime}\right) \wedge \mathrm{p} \cap \mathrm{q}(\mathrm{w})\right] \rightarrow \mathrm{w}^{\prime} \leq_{\mathrm{M}} \mathrm{w}\right)\right] \wedge \mathrm{q}\left(\mathrm{w}_{@}\right)\right] \\
& \text { not-at-issue content assertion }
\end{aligned}
$$

In (4), M ranks the set of $\neg q$ worlds as worlds that are considered to be more likely than $q$ worlds, according to the speaker's beliefs. The felicitous mirative sentence also asserts $q$ as true in the actual world.

The accessibility relation $\mathrm{R}$ provides the right modal base (set of worlds $\mathrm{w}^{\prime}$ that are compatible with the speaker's doxastic domain with respect to a world of evaluation $\mathrm{w}_{@}$ and a certain time).

What the mirative operator $\mathrm{M}$ does is to relate two set of worlds: the set of worlds compatible with prior beliefs and the set of worlds denoted by the assertion. The clash occurs by $\mathrm{M}$ ranking the set of $\neg q$ worlds as better worlds than $\mathrm{q}$ worlds. The factivity expressed by the assertion is captured by the final conjunct in the meaning of $\mathrm{M}$.

Syntactically, I place the operator $\mathrm{M}$ in the $\mathrm{CP}$ domain. This is because mirativity does not contribute to the interpretation of the proposition. Following the literature on the topic (Potts 2005), I claim that mirativity is an above-theproposition phenomenon, namely, it contributes not-at-issue information, since it cannot be negotiated or directly negated. 
In (5), we see that the speaker cannot cancel the surprise, neither can the hearer deny it (6). It can be indirectly challenged, as it is in (7) as a follow up to the mirative sentence 'Juan fumaba!' ('Juan smokes!').

\#Pero no me sorprende. ('But I'm not surprised.')

(6) \#No, no estás sorprendido. ('No, you're not surprised.')

(7) ¡Pero si ya te lo había dicho! ('But I’ve already told you that!’)

We can safely say then that mirativity contributes not-at-issue or backgrounded content, since the main assertion is the declarative content of the sentence. It seems appropriate to take out mirativity from the assertion domain (TP in the syntax) and place in the CP domain. Besides, the interaction between mirativity and negation supports the idea that the former takes scope above the proposition (8), given that in Spanish, negation is above TP.

No eras alto!

Neg PastImp.2sg tall

'I am surprised you're not tall' / \#'I am not surprised you're tall'

\section{Real past tense}

Iatridou (2000) observes that crosslinguistically, the past tense morphology presented in counterfactuals fails to receive a past interpretation. In present counterfactuals as in If he had money, he would buy a car, the antecedent receives a present interpretation and in past counterfactuals as in If he had had money, he would have bought a car, the pluperfect in the antecedent is not the past of the past, but rather a simple past.

This failure of past interpretation applies to miratives as well. In the imperfect mirative, there's no such past tense interpretation. In (1a), repeated here in (9), the proposition refers to the actual state of affairs, namely, a present situation: Juan has the habit of smoking in the present. However, the verbal morphology is in past tense.

(9) ¡Juan fumaba!

smoke-past.imp.3sg

'Juan smokes.'

In a context in which the true imperfect arises, the mirative meaning is cancelled or gets neutralized, as in (10). In order to assign a surprise meaning, we would need some admirative marker (such as "Oh") or exclamation intonational contour. 


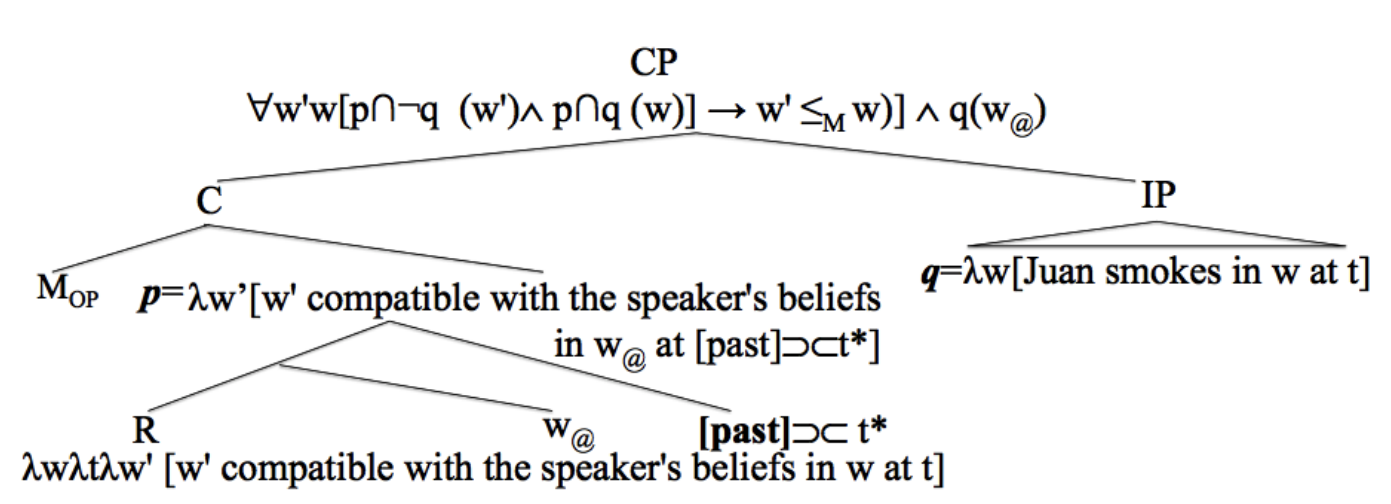

Figure 1 The role of past tense in mirativity
a. \#Oye, Juan fumaba
hace 10 años!
Hey Juan smoke.past imp 3sg ago 10 years
'Hey, Juan used to smoke!' (to my surprise)

Now, the literature of fake past tense understands it as a metaphor of remoteness (Fleishman 1981), or as mark of non actual worlds (Iatridou 2000). However, I claim that the so called fake tense encountered in miratives is in fact real temporal past. In this sense, I follow Ippolito's (2003) analysis of fake past in counterfactuals.

My proposal is that the past tense is not interpreted in the proposition (TP), but rather is interpreted higher (CP) as the time argument of the modal base (speaker's beliefs). Therefore, in mirativity, [past] represents the speaker's past beliefs up to the discovery time in which she realizes that the actual state of affairs contradicts her previous beliefs.

Consider what happens in the imperfect case: the past tense is interpreted under the modal operator $\mathrm{M}$. The proposition then remains timeless and thus gets a present default interpretation. For the pluperfect case, the second past tense layer is interpreted in the proposition generating the past episodic reading (a similar analysis to the one Iatridou proposes for the second past layer in past counterfactuals).

Building up the implementation, let's see in Figure 1 how [past] gets incorporated into in the picture.

In Figure 1, the operator $M$ will take as argument the modal base R. R (set of speaker's beliefs) takes as arguments a world and a time. The time gets the value of [past] (displaced from IP/TP, or as agreement between $\mathrm{C}$ and T). ${ }^{1}$ In the end, $\mathrm{R}$

${ }^{1}$ See Torres 2011 for a development of this syntactic analysis for Albanian miratives. 
is the set of speaker's beliefs in the actual world, but in a past time that abuts with the speech time $t^{*}$, which is also the discovery time. The asserted proposition also has a time argument that ends up unbounded, and thus, gets a present interpretation by default. To conclude this section, I have shown how tense in miratives is interpreted as real tense. I now will extend the analysis to the pluperfect mirative.

\section{The pluperfect mirative}

In Andean Spanish, the pluperfect can express surprise about past episodic events (11-12) or states (13a-b) which can refer to either present states or past states, depending on the context.

(11) ¡Juan habia fumado! Juan aux-3sg smoked

'Juan smoked!' (Context: you thought Juan didn't smoke at the party, but then you see ashes on his clothes,)

(12) ¡Te habías casado!

2 sg aux.2s get.married

'You got married!' (I didn’t know it.) (Laprade 1981: 223)

a. ¡Juan había sido alto!

Juan aux-3s been tall

'Juan was tall!' (Context: Looking at pictures of Juan, who is short as an adult, when he was a child. Or at Juan's funeral looking how large his coffin is.)

b. ¡Juan había sido alto!

Juan aux-3s been tall

'Juan is tall!' (Context: looking at Juan standing.)

For the pluperfect mirative, the tense also appears to be fake. (11-12) does not refer to the present as the miratives we have looked at so far. However, it does not have a past of the past interpretation either (the meaning of standard pluperfects, as shown in (14)). It just has a simple past interpretation (as a preterite).

(14) Cuando llegué a la fiesta, Juan había fumado todos los cigarrillos. when arrived to the party Juan had smoked all the cigarrettes 'When I arrived to the party, Juan had smoked all the cigarettes.'

Again, as we discussed regarding the imperfect, in a context in which the pluperfect arises, the mirative meaning is cancelled or gets neutralized, as in (15). 
Real tense and real aspect in mirativity

In order for (15) to get a surprise meaning, there is need for some admirative marker or exclamation intonational contour.

\#Ayer cuando llegué, ¡María ya había comprado las yesterday when arrive.3sg.preterite Maria already had bought the verduras!

vegetables

'When I arrived yesterday, María had bought the vegetables!' (to my surprise)

Neither of the states in (13) gets a standard pluperfect interpretation. (13a) gets a past interpretation, without overt framing, and (13b) receives a present interpretation, similar to the imperfect statives we presented in the introduction. We are going to discuss statives in section 6 , so we can leave them aside for the moment.

Traditionally, the pluperfect has been analyzed as having two layers of past. If we follow this analysis, then one layer of past can be displaced to the mirative domain, as the time argument of the modal base, and the second past tense layer is interpreted in the proposition generating the past episodic reading (a similar analysis to Iatridou's proposal for past counterfactuals). So, unlike imperfects, the tense in the proposition is not valued by default with the utterance time, but rather it has a [past] value, given by the second layer of pluperfects. Apart from this, the analysis provided is the same as for the imperfect mirative.

In summary, eventive pluperfect miratives use one past tense layer for the mirative meaning (time argument of the modal base) and its past episodic meaning from the other past tense layer.

Now that I have presented the main structure of the analysis and taken care of the past tense morphology, let's see how the aspectual meanings these forms bear get in the picture.

\section{The role of aspect and association with focus}

\subsection{Aspect in miratives}

In Spanish, the past imperfect can be used for habitual and generic meanings. ${ }^{2} \mathrm{I}$ have shown that in the imperfect mirative, the past tense morphology contributes to the mirative meaning, and not to the tense value in the assertion. However, aspect keeps its usual interpretation, as we can see in (1a), repeated below as (16), and (17).

\footnotetext{
${ }^{2}$ And when appropriately framed, it can also generate progressive readings, a meaning which is not available for the mirative.
} 
Torres Bustamante

(16) ¡Juan fum-aba!

smoke-past.imperf.3sg

'Juan smokes!' (Context: you see Juan lighting a cigarrete, and you realize he has the habit of smoking, something that you didn't expect.)

(17) ¡Los gatos mordían!

the cats bite-past.imperf.3pl.

'Cats bite!' (Context: you didn't expect cats to bite.)

As we see, (16) has a (present) habitual meaning, and (17), a (present) generic meaning, something that is not unexpected, since these are readings the imperfect can get in Spanish.

With respect to the pluperfect, things are similar. Both (11), repeated below as (18), and (19) convey a perfect(ive) meaning. This is compatible with the standard pluperfect, which is used for events that have occurred (and culminated) before another time in the past.

¡Juan había fumado!

Juan aux-past.3sg smoked

'Juan smoked!' (Context: you thought Juan didn't smoke at the party, but then you see ashes on his clothes.)

¡Habías traído la cámara!

aux-past.2sg brought the camera

'You brought the camera!' (Context: you thought Juan didn't bring the camera to the party, but on leaving, you saw the camera on his pocket.)

Now, if we pay attention to the contexts these sentences need in order to be felicitous, we notice that the imperfect mirative requires the speaker only to not expect or consider likely what she discovers at speech time. Thus, in (16) it is not that the speaker had a specific belief about Juan's habit of smoking, but due to certain generic beliefs, the speaker was not expecting Juan to be a smoker (for example, the speaker knows Juan is healthy, and knows also that healthy people usually don't smoke). Or with respect to cats, the speaker simply was not expecting cats to bite, maybe because she knows cats scratch and that biting is associated with dogs instead of cats.

In the pluperfect cases, the surprise is due to the speaker's specific belief that Juan didn't smoke at the party, or that Juan didn't bring the camera. In that sense, what the speaker encounters at discovery time is something that contradicts her previous beliefs, while in the imperfect case, it is something that didn't follow from her previous beliefs.

I claim that these differences in meanings have to do with the aspectual form of these miratives. The imperfective morphology yields surprise due to unlikelihood, while the perfect(ive) morphology yields surprise due to counter 
Real tense and real aspect in mirativity

expectations. So, besides contributing with its normal meanings to the assertion, aspect also plays a role in the mirative domain.

How do we account for this connection between imperfect and unlikelihood, and pluperfect and counter expectations? Following a suggestion by Veneeta Dayal (p.c.), I analyze the role of aspect as influencing the choice of generic vs. episodic beliefs and use focus semantics to impose an ordering on the worlds of the modal base. In a nutshell, aspect shapes the propositions in the modal base in miratives. Thus, the imperfect requires the speaker's beliefs to be also generic/habitual, beliefs such as 'Cats don't bite', or 'Healthy people don't smoke'. As for the pluperfect, the speaker's beliefs that are going to be contrasted with the assertion (discovery) take the shape of perfect(ive) events, such as 'Juan didn't smoke at the party', 'You didn't bring the camera', etc. This different set of beliefs (that mirror the aspectual morphology of the assertion) has consequences for the surprise effect these sentences trigger. As I said, I will implement this idea in my main structure via focus semantics.

\subsection{Mirativity and Focus}

Focus highlights certain constituents in a sentence (via accent or syntactic means). Semantically, focused constituents are interpreted with respect to a set of alternatives provided by the context (Rooth 1992) .

My claim is that mirative sentences are always focused as in (20), in which, in absence of any overt correlate ${ }^{3}$, the whole IP bears a focus index.

a. [iJuan fumaba! $]_{F}$

b. [¡Juan había fumado! $]_{\mathrm{F}}$

The set of alternatives the propositions above contrasts with are salient via focus. This set contains propositions that preserve the aspectual morphology of the assertion ${ }^{4}$.

In (20a), the set of alternatives consists of imperfective propositions, which yields generic/habitual sentences, while in (20b) the set consists of perfect(ive) propositions, which yields episodic sentences or result states.

\footnotetext{
3 Although mirative sentences are usually uttered as exclamations or along with certain discourse markers such as Wow! or Look!

4 A similar analysis is made by Ogihara (2000) with respect to 'mismatched' counterfactuals: sentences with past perfect morphology but with adverbs that make reference to the future. In his analysis, these adverbs are focused and bring up a set of alternatives that contains a salient sentence that contrasts with the assertion. This sentence bears the past perfect morphology.
} 
The proposal is that one proposition in this set of alternatives will order the worlds in the modal base. Our first version of the M operator states that worlds $w$ ', in which $\neg q$ holds, are better worlds than worlds $w$, in which $q$ holds. Now that we have put aspect and focus in the analysis, let's refine this ordering.

Focus brings up a set of alternatives; for instance, in the pluperfect case, this set of alternatives contains propositions such as \{Juan smoked at the party, Juan didn't smoke at the party, Bill smoked at the party, .... . Suppose we take 'Juan didn't smoke at the party'. This proposition will make worlds w' better than worlds w, in which the assertion 'Juan smoked at the party' holds. As we see, the assertion will trigger surprise, since in the speaker's past beliefs, the ordering of worlds didn't support the assertion. Now, suppose we pick 'Juan smoked at the party'. This belief is compatible with the assertion, then no surprise arises and thus mirativity fails, since this sentence won't give the right ordering. Finally, if we pick a sentence like 'Bill smoked at the party', this sentence is irrelevant with respect to the discovery (that John smoked at the party), so no ordering can be done. However, it could also be the case that the speaker didn't believe that Juan didn't smoke at the party, but the set of alternatives can contain it. If this happens, as in the first case, mirativity won't be adequately defined. Given these cases, we need to specify that the proposition we pick from the set of alternatives, in order to do the ordering of worlds required for mirativity, should meet two properties. First, it must be different from the assertion and second, it needs to be part of the modal base.

Before discussing in detail the imperfect case, let's update the $\mathrm{M}$ operator, which is defined now in (21).

$$
\begin{aligned}
& \mathrm{M}_{\mathrm{op}}=\lambda \mathrm{p} \lambda \mathrm{q} \cdot \exists \mathrm{q}^{\prime}: \mathrm{q}^{\prime} \neq \mathrm{q} \wedge \mathrm{C}\left(\mathrm{q}^{\prime}\right) \wedge \mathrm{p} \subseteq \mathrm{q}^{\prime} \cdot\left[\left[\forall \mathrm{w}^{\prime} \mathrm{w}\left[\mathrm{p} \cap \mathrm{q}^{\prime}\left(\mathrm{w}^{\prime}\right) \wedge \mathrm{p} \cap \mathrm{q}(\mathrm{w})\right]\right.\right. \\
& \left.\left.\left.\rightarrow \mathrm{w}^{\prime} \leq_{\mathrm{q}}, \mathrm{w}\right)\right] \wedge \mathrm{q}\left(\mathrm{w}_{\varrho}\right)\right]
\end{aligned}
$$

In (21), the $\mathrm{M}$ operator introduces the proposition $q$ '. This proposition $q$ ' is different from the assertion $\left(q^{\prime} \neq q\right)$, and is taken from the set of alternatives $\mathrm{C}-$ the focused assertion- $\left(\mathrm{C}\left(q^{\prime}\right)\right)$. We also need to include that the proposition $q^{\prime}$ is part of the speaker's beliefs $\left(p \subseteq q^{\prime}\right.$ ). Now, the ordering we want-worlds $w^{\prime}$ better than worlds $w$-is done by the proposition $q$ ' we picked from the set of alternatives. And since the operator also asserts $q$ as true in the actual world, the clash happens and the speaker gets surprised.

We can also include in the set of alternatives the superset the individual belongs to. For instance, the speaker believes Juan is healthy and that healthy people don't smoke. If we include the pluperfect case, a sentence like 'Healthy people didn't smoke at the party', then we can take this proposition and still get the desired effect: counter expectation on discovering that Juan, as one of the set of healthy people, did smoke at the party. 
Real tense and real aspect in mirativity

If we extend this analysis to the imperfect case, the proposal goes through as well. In this case, the set of alternatives consists of generic and habitual sentences, for instance, for the sentence in (20a), we get this set of alternatives: \{Juan smokes, Healthy people smoke, Healthy people don't smoke, Bill smokes...\}. The proposition $q$ ' that will get us the right ordering is 'Healthy people don't smoke', and since the speaker believed Juan is healthy, then the discovery of Juan being a smoker triggers surprise. In this case, I have talked about unlikelihood, namely, the speaker wasn't expecting Juan to be a smoker, given her generic beliefs, but, as is well-known, generic (and habituals) sentences allow for exceptions (Krifka et al. 1995). Therefore, even though Juan turns out to be a smoker, it is not something that requires the speaker to revise her beliefs, unlike the pluperfect case. ${ }^{5}$ We will see in the next section on statives, how this contrast is clearly expressed.

A final remark regarding the analysis of the imperfect case, before turning to the full derivation. We haven't excluded the sentence 'Juan doesn't smoke' from the set of alternatives and, in fact, it can be picked and the sentence will still be felicitous. We will get counter expectations in this case, but related to a belief regarding Juan's habits, so the aspectual morphology is still preserved. This reading may be available for some Spanish speakers.

In summary, I have argued in this subsection that aspect contributes to the meaning of the proposition, but also, via focus, it determines the shape of the propositions in the set of alternatives. One of these propositions will order the worlds in the modal base. This way, unlikelihood is associated with the imperfect mirative (given that the proposition $q^{\prime}$ is a generic or habitual belief) and counter expectations are related to the pluperfect (given that $q$ ' is episodic or a result state).

\subsection{Implementation}

In figure 2, a full derivation of the mirative sentence ;Juan fumaba! ('Juan smokes!') is provided. As we discussed earlier in the paper, the past tense is not interpreted in the proposition (IP), but rather is interpreted higher as the time argument of R. R also takes as an argument the actual world, which is the world of evaluation. The surprise operator gets fed by $p$ (modal base with world and time arguments) and $q$, the assertion. But in order for the operator to rank the worlds, a proposition $q$ ' is needed. This proposition comes from the set of alternatives $\mathrm{C}$ (the focus value of IP: $\llbracket I P \rrbracket^{\mathrm{F}}$ ). So, in the tree, the ordinary semantic value of IP provides the assertion, while the focus value of IP provides the ordering source. In [1] the operator takes the modal base $p$ and in [2] the assertion

\footnotetext{
${ }^{5}$ Thanks to Veneeta Dayal for pointing out this idea to me.
} 


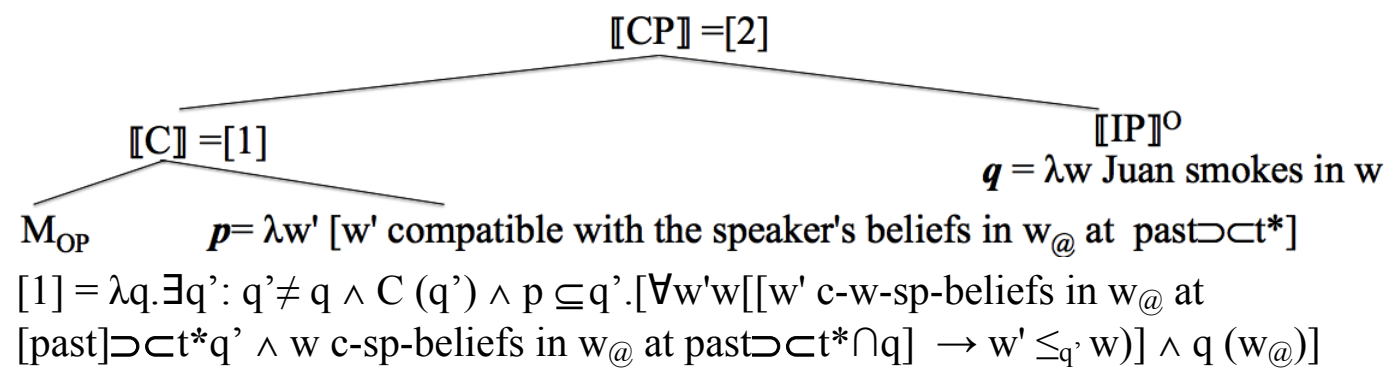

[2] $=\forall w^{\prime} w\left[\lambda w^{\prime}\left[\left[w^{\prime}\right.\right.\right.$ is compatible with the sp. beliefs in $w_{@}$ at [past] $\left.\supset \subset t^{*}\right] \cap \lambda w$ [Healthy people don't smoke in $w]\left(w^{\prime}\right) \wedge \lambda w^{\prime}\left[w^{\prime}\right.$ is compatible with the sp. beliefs in $\mathrm{w}_{@}$ at [past] $\left.\supset \subset \mathrm{t}^{*}\right] \cap \lambda \mathrm{w}[$ Juan smokes in $\left.\left.\mathrm{w}](\mathrm{w}) \rightarrow \mathrm{w}^{\prime} \leq_{\mathrm{q}^{\prime}} \mathrm{w}\right)\right] \wedge$ Juan smokes in $\left.\mathrm{w}_{@}\right]$

$\mathrm{C}=\llbracket \mathrm{IP} \rrbracket^{\mathrm{F}}=\{\lambda w$ Juan smokes in $w, \lambda w$ Juan doesn't smoke in $w, \lambda w$ Healthy people smoke in $w$, $\lambda w$ Healthy people don't smoke in $w$ \}

Figure 2 Derivation of '¡Juan fumaba!'.

and the alternate proposition is plugged in. [2] provides us with the meaning of the mirative sentence 'Juan fumaba!'.

For the pluperfect case, the derivation is almost the same but, crucially, what differ are the values of $\llbracket I P \rrbracket^{O}$ and $\llbracket I P \rrbracket^{\mathrm{F}}$. The ordinary semantic value will be the episodic proposition 'Juan smoked at the party' and the focus value will consist of sentences like \{Juan smoked at the party, Juan didn't smoke at the party,...\}. In the end, we pick 'Juan didn't smoke at the party', which is the proposition $q$ ' that ranks the worlds in the way a clash with the assertion is generated.

\section{Pluperfect statives: unexpected present interpretation}

\subsection{Two layers of past}

The analysis for pluperfect eventives that I have given above assumes two layers of past: one goes to the mirative domain, while the other stays in the proposition and yields the past episodic interpretation. Schematically this is shown in (22).

$$
\left[\mathrm{PAST}_{1} \ldots .\left[\mathrm{T} \mathrm{t}_{1} \ldots . . .\left[\mathrm{v} \ldots \mathrm{PAST}_{2} \ldots . .\right]\right]\right]
$$

In statives, this also holds as we saw in (13a), repeated here as (23), 
Real tense and real aspect in mirativity

(23)

¡Juan habia sido alto!

Juan aux-3sg been tall

'Juan was tall!' (Context: Looking at pictures of Juan, who is short as an adult, when he was a child. Or at Juan's funeral looking how large his coffin is.)

In (23) we understand that the property denoted by the individual level predicate 'being tall' is over. The analysis in (22) clearly extends to (23).

\subsection{Apparent problem}

However, the most natural context to utter a pluperfect stative is the one in (13b), repeated here in (24), in which we understand that the property holds in the present.

(24) ¡Juan habia sido alto! Juan aux-3sg been tall

'Juan is tall!' (Context: looking at Juan standing.)

I will show that (24) is not a counterexample to (22). I will argue that in both (23) and (24) the interpretation of the property being over or not is due to the interaction of the evidence at the speech time and lifetime effects. Let's start by presenting the central ideas about lifetime effects and stative predicates from Musan 1997.

\subsection{Statives and lifetime effects}

Musan (1997) shows that individual-level predicates behave differently from stage-level predicates in past tense clauses, with respect to the lifetime of their subjects.

(25) Gregory was from America.

(26) Gregory was happy.

(25) implicates that Gregory is dead, but (26) does not. This is so because stage-level predicates refer to temporary properties of an individual, while individual-level predicates cover long-time properties of an individual, usually the whole existence time. Musan explains the lifetime effects associated with (25) as an implicature that arises due to maximal informativeness. Since a sentence like 'Gregory is from America' is more informative than (25), the choice of (25) 


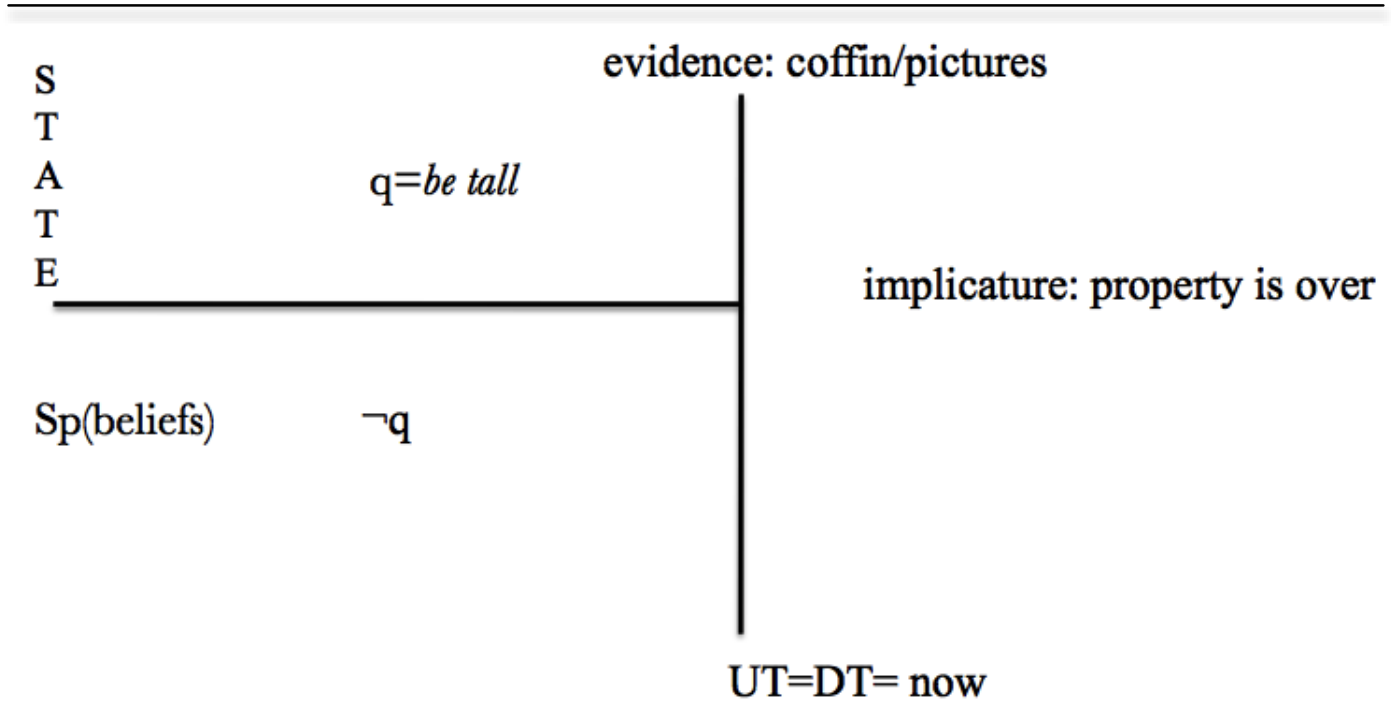

Figure 3 iJuan habia sido alto! (in the past)/ 'Juan was tall!'

cannot be felicitous if Gregory is still alive (in that case, the speaker should have chosen 'Gregory is from America'). Then, the speaker chooses (25) because he is implicating that the property in question is over. Since the property is an individual-level predicate that holds for the life duration of Gregory, the speaker implicates that Gregory is dead. Only in a context when there is a past wellframed interval, this lifetime effect doesn't arise, for instance, in a sentence like 'I was introduced to Gregory. He was from America'.

Now, let us return to miratives and see how lifetime effects play out in the stative constructions. I claim that, in fact, in all the relevant cases the assertion, strictly speaking, is about a time in the past.

In (23) and (24), we are dealing with an individual-level stative predicate such as 'being tall'. We expect it to trigger lifetime effects. However, in (23) the discovery time provides evidence that frames the past interval and we interpret the property as being over without the subject being dead, for example in the context in which we are looking at pictures of Juan when he was a child. In the coffin context, we get both implicatures: the property is over and the subject is dead. This is illustrated in Figure 3. We see that the semantics of 'was tall' only asserts that the property held in the past. It is the evidence available at the utterance time/discovery time that triggers the implicature that it doesn't hold in the present, namely, that the property is over. 


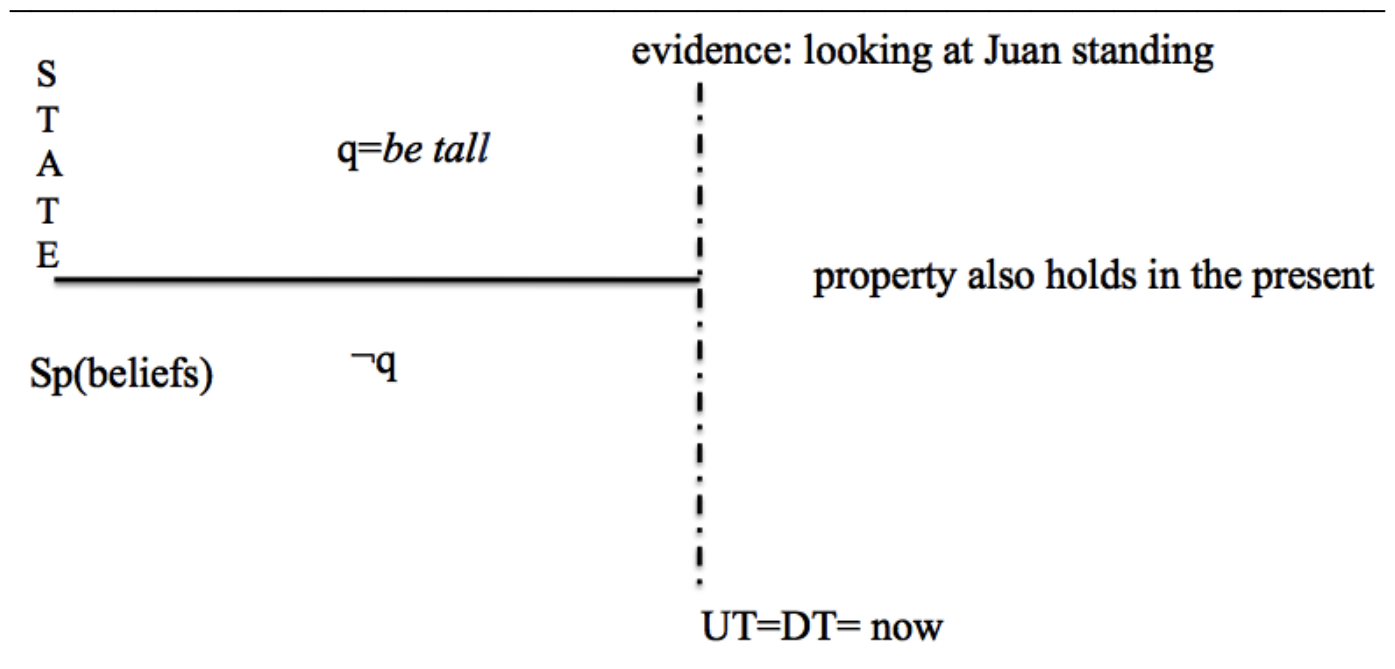

Figure 4 ¡Juan habia sido alto! (in the present)/ Juan is tall!

Let's see now the interpretation of (24), in which the same stative 'was tall' gets a present reading, in absence of any overt time frame. Extending the analysis above, I claim that in (24) the semantics is the same as in (23): the property held in the past. What is puzzling is why (24) does not implicate that the property is over; on the contrary, we understand that the property still holds.

In (24), the implicature of the property being over fails to arise because of the nature of the evidence. The context is one in which the speaker sees Juan standing, so the speaker knows Juan is alive. We get then a present interpretation in order to prevent the predicate from triggering lifetime effects. In absence of a time framing, interpreting that the property is over would implicate that the subject is dead (since 'being tall' is an individual level predicate) and this would be inconsistent with the evidence. This is illustrated in Figure 4, in which the property is not closed in the past, but rather it extends to the present, given the context.

As stated above, a stage level predicate such as 'being happy' does not trigger lifetime effects. If this is the case, we expect that the default interpretation for a mirative sentence like ¡Juan habia estado feliz! ('Juan was happy!') is that the property is over, which is borne out. In a context in which Juan is still smiling, such a sentence would sound odd.

In summary, a pluperfect stative in a mirative sentence only tells us that the state holds in the past, but the interpretation that the property is over or that it still holds in the present depends on the interaction between the evidence provided by 
the context at the discovery time and whether the predicate triggers lifetime effects (individual level predicates vs. stage level predicates).

\subsection{Further confirmation}

In this section I want to look at a further contrast between two minimally contrasting pairs of mirative sentences (1b), repeated below in (27), and (13b), repeated in (28), which differ only in aspectual morphology. As we see, the reading is the same for both sentences 'Juan is tall', but it is (28), the one with pluperfect morphology, that triggers a stronger sense of surprise.

$$
\text { ¡Juan era alto! }
$$

Juan be.past.imp.3sg. tall

'Juan is tall!'

(28) ¡Juan habia sido alto!

Juan aux-3sg been tall

'Juan is tall!'

Why do we get this contrast in terms of degree of surprise? I claim that this distinction has to do with the difference between unlikelihood vs. counter expectations.

In (27), the surprise is about Juan being tall in contrast with a certain class that he belongs in and that makes the speaker expect Juan not to be tall. For instance, we know Peruvians are short and we know Juan is Peruvian, but when we met him, we realized that surprisingly he is tall for a Peruvian. The set of alternatives then contains propositions such as \{Peruvians are tall, Peruvians aren't tall...\}. As we suggested before, generic beliefs allow for exceptions. Thus, the speaker can still accommodate the discovery of Juan being tall, despite being a Peruvian at the same time. This could explain why, when contrasting the pluperfect in a minimal pair, the imperfect generates a lesser degree of surprise.

In (28), there is a counter expectation reading (the speaker had the idea of Juan being short). The set of alternatives must contain propositions in the form of perfect aspect (that is compatible with states) such as \{Juan has been tall, Juan has not been tall\}. In this case, the speaker needs to revise her beliefs, so more suprise arises.

This minimal pair then not only allows us to offer further support to the proposal on the role of aspect in miratives, but also confirms that the pluperfect stative is not a 'defective' pluperfect but rather it keeps its features, thus triggering the expected mirative meaning. The present interpretation that we see in some cases is due to the interaction between individual level predicates, the context and lifetime effects. 
Real tense and real aspect in mirativity

\section{Conclusions}

The $\mathrm{M}$ operator was proposed as a way to model surprise related to mirativity. I define this surprise as the clash between the speaker's previous beliefs and the current state of affairs. $M$ ranks the worlds in which the assertion does not hold as better than the ones in which it does, but $\mathrm{M}$ also asserts $q$ as true in the actual world, and thus the clash arises.

The role of past tense and aspect morphology in Spanish miratives are seen in this proposal as contributing to the mirative meaning. However, I do not appeal to different temporal/aspectual semantics. I claim that tense and aspect convey their usual meaning. The past tense is interpreted outside the proposition, as the time argument of the modal base. Aspect shapes the propositions in the set of alternatives (available via focus). One proposition from this set is used to order the worlds in the modal base. This analysis allows us to explain the contrast between the imperfect mirative and the pluperfect one in Spanish.

I have argued for an analysis of mirativity that takes as central piece of its meaning the tense/aspect morphology. Further work is needed to evaluate the extension of this proposal to other mirative paradigms and its relationship with other constructions that also express surprise, such as exclamations and exclamatives.

\section{References}

Delancey, Scott. 1997. Mirativity: the grammatical marking of unexpected information. Linguistic Typology 1:33-52.

Fleischman, Suzanne. 1989. Temporal distance: a basic linguistic metaphor. Studies in Language 13:1-50.

Iatridou, Sabine. 2000. The grammatical ingredients of counterfactuals. Linguistic Inquiry 31: 231-270.

Ippolito, Michela. 2003. Presuppositions and implicatures in counterfactuals. Natural Language Semantics 11:145-186.

Krifka, Manfred et al. 1995. Genericity: An Introduction. In G.N. Carlson and F.J. Pelletier (eds.) The Generic Book, 1-124. Chicago and London: University of Chicago Press.

Laprade, Richard. 1981. Some cases on Aymara influence on La Paz. In Hardman, Martha (ed.) The Aymara Language in Its Social and Cultural Context, 207-227. Florida: University of Florida Press.

Musan, René. 1997. Tense, predicates, and lifetime effects. Natural Language Semantics 5: 271-301.

Ogihara, Toshiyuki. 2000. Counterfactuals, temporal adverbs, and association with focus. In Brendan Jackson and Tanya Matthews (eds.) Semantics and Linguistics Theory (SALT) 10, 115-131. Ithaca, NY: CLC. 
Potts, Christopher. 2005. The Logic of Conventional Implicatures. Oxford: Oxford University Press.

Rooth, Mats. 1992. A theory of focus interpretation. Natural Language Semantics 1:75-116

Torres Bustamante, Teresa. 2011. Mirativity as tenselaspect displacement. NELS 42, U. of Toronto.

Teresa Torres Bustamante

18 Seminary Place

Rutgers University

New Brunswick, NJ 08901

teresatb@,rutgers.edu 